\title{
GESTÃO DE TUTORIA: o papel do Supervisor de Tutoria
}

Thiago Soares Nunes - Universidade Federal de Santa Catarina adm.thiagosn@gmail.com

Edivandro Luiz Tecchio - Universidade Federal de Santa Catarina edivandro@gmail.com

Marcos Baptista Lopez Dalmau - Universidade Federal de Santa Catarina dalmau@cse.ufsc.br

Suzana da Rosa Tolfo - Universidade Federal de Santa Catarina - srtolfo@cfh.ufsc.br

Andressa Sasaki Vasques Pacheco - Universidade Federal de Santa Catarina andressa.ufsc@gmail.com

Marina Keiko Nakayama - Universidade Federal de Santa Catarina marina@egc.ufsc.br

\section{RESUMO}

A expansão da educação superior no Brasil, devido à sua extensão territorial, é um desafio para os governantes. Sendo assim, com esse crescimento exponencial, necessitase de um planejamento e controle adequado. Em busca de informações sobre o sistema de um curso de graduação na $\mathrm{EaD}$, este trabalho objetivou apresentar e descrever o papel do Supervisor de Tutoria. Quanto aos procedimentos metodológicos caracteriza-se como: descritivo, ex-post-facto e estudo de caso, com abordagem qualitativa. Pode-se verificar que o papel do supervisor de tutoria pode melhorar significativamente a eficiência na comunicação, bem como agiliza o sistema de decisão. Além disso, melhora a qualidade das relações entre tutores, alunos e gestores do curso, bem como permite uma visualização de crescimento para carreira dos tutores.

Palavras-chaves: educação a distância. supervisor de tutoria. tutoria. EAD.

\section{ABSTRACT}

\section{TUTORIAL MANAGEMENT: Tutorial Supervisor function}

The expansion of the superior education in Brazil, due to its territorial extension, is a challenge for the governing. In this way, with that exponential growth, a planning and appropriate control is needed. In the search of information about the system of a degree course in the distance modality, this article aimed to present and describe the Tutorial Supervisor's paper. About the methodological procedures it is characterized as: description, ex-post-facto and case study, with qualitative boarding. We conclude that the Tutorial Supervisor's provides a significantly efficiency in the communication, as well as a faster system of decision. Moreover, improves the quality of the relationships between tutors, students and managers of the curse, and allows a visualization of growth for tutors.

Keywords: distance education. tutorial supervisor's. tutorial.

\section{INTRODUÇÃO}

A educação a distância está cada vez mais presente na sociedade contemporânea. Ela apresenta-se como uma modalidade de educação adequada e necessária para atender as demandas educacionais da sociedade do conhecimento. De acordo com Aretio (2002) a educação a distância que é praticada hoje não é a mesma (nem seus objetivos) de 150 anos atrás, nem se entende a educação a distância da mesma maneira em diferentes contextos geográficos ou institucionais na atualidade. Contudo, "a ideia básica de educação a distância é muito simples: alunos e professores estão em locais diferentes 
durante todo ou grande parte do tempo em que aprendem e ensinam" (Moore; Kearsley, 2007, p. 1).

Nesse sentido, pode-se conceituar educação a distância, segundo Simonson (2006), como uma educação formal que tem como base uma instituição na qual o grupo de aprendizagem está separado e se utilizam tecnologias de comunicação para conectar os alunos, recursos e instrutores.

A gestão de um programa de educação na modalidade a distância compreende diversas dimensões e envolve uma equipe multiprofissional. As aderências necessárias entre as diferentes instâncias de planejamento e gestão e o comprometimento dos envolvidos são bases para um programa dar certo. Além disso, a definição de objetivos, metas, valores, competências, recursos, entre outros procedimentos podem garantir a dinâmica e ao mesmo tempo a estabilidade do programa (Moraes et al., 2007).

Rumble (2003) aponta que a gestão de um curso de educação a distancia é um processo que permite conduzir o desenvolvimento das atividades com eficiência e eficácia. O gestor é responsável pelo planejamento, organização, direção e controle. A UNESCO (1997) complementa que a gerência e a administração eficiente requerem não apenas uma equipe competente, mas também sistemas e rotinas administrativas bem definidas e eficientes. Portanto, cursos que disponham de uma equipe multidisciplinar, com profissionais preparados para atuar na educação a distância e uma gestão eficiente e eficaz têm melhores condições de oferecer uma educação a distância de qualidade.

A organização desta equipe multidisciplinar pode estar dividida em quatro grandes grupos, segundo Moraes et al. (2007): equipe pedagógica; equipe de suporte e infraestrutura; equipe de acompanhamento; e equipe de apoio. A equipe de apoio é também subdividida em três grupos: produção de materiais, coordenação de ambiente virtual de ensino aprendizagem - AVEA e tutoria. A literatura apresenta que a tutoria é composta pelo coordenador de tutoria, tutores presenciais e a distância. Contudo, além dos cargos supracitados no modelo analisado acrescenta-se outro cargo, o Supervisor de Tutoria, que executa atividades administrativas que correspondem tanto ao nível estratégico quanto gerencial.

Em 2006 com o curso piloto de graduação em administração, na modalidade a distância, apresentava um número de 654 alunos matriculados. Em 2007, aconteceram dois vestibulares para outros novos projetos: projeto piloto 2, abertura de 400 vagas e projeto UAB com 600 vagas. Por fim, em 2009 houve a inserção de outro projeto ofertado à distância - curso em Administração Pública, que disponibilizou 300 novas vagas. Assim, de 2006 a 2009, a tutoria teve um aumento considerável no número de alunos, bem como na sua estrutura de apoio.

A pesquisa ocorreu em uma tutoria de um curso de Graduação em Administração ofertada na modalidade a Distância, que é um projeto da Universidade Aberta do Brasil, presente em 25 pólos espalhados por diversos estados do Brasil, e abrange aproximadamente 1.650 alunos e 42 tutores.

Dessa maneira, com base no contexto apresentado, este artigo tem como objetivo apresentar e descrever o papel do Supervisor de Tutoria, com base em uma tutoria de um curso de graduação na modalidade a distância, tendo em vista a importância desta função para melhoria no funcionamento do curso e dos processos/atividades realizados em âmbito estratégico, gerencial e também operacional dentro da tutoria e do curso.

\section{METODOLOGIA}

Gil (2007) propõe a categorização da pesquisa quanto aos objetivos, à abordagem e aos procedimentos. Quanto aos objetivos, caracteriza-se como uma 
pesquisa descritiva, a qual procurou apresentar e descrever o papel do Supervisor de Tutoria através de alguns fluxogramas de processos das suas principais atividades. Além disso, tem-se uma abordagem qualitativa.

Já em relação aos procedimentos adotados na coleta de dados, esta pesquisa é classificada como bibliográfica, documental, ex-post-facto e estudo de caso. Foi realizada uma pesquisa documental a partir do projeto pedagógico do curso e feita uma meta pesquisa em artigos, monografias, dissertações e teses. A pesquisa foi realizada na tutoria do curso de Graduação em Administração, ofertado na modalidade a distância, da UFSC.

A obtenção de dados foi esquematizada de acordo com os objetivos. Os dados primários foram coletados por meio de entrevistas com seis Supervisores de Tutoria que atuam ou atuaram nesta função, deste modo com a descrição das atividades exercidas foi possível definir fluxogramas de suas funções.

Por fim, a partir da análise do discurso dos pesquisados e da vivência dos pesquisadores nas atividades deste curso foi possível correlacionar o descrito nas entrevistas com o vivido, assim, equiparando pontos positivos e críticas quanto às atividades exercidas pelos Supervisores de Tutoria.

\section{GESTÃO DE TUTORIA: O SUPERVISOR DE TUTORIA}

A educação a distância não é algo novo. Ela vem evoluindo e desenvolvendo-se de acordo com as diferentes tecnologias de cada época, tendo como ideia central a separação temporal e espacial entre professor e aluno. Entretanto, apesar das suas peculiaridades, a educação a distância muitas vezes é comparada com o ensino presencial, o que acarreta em uma forma de gestão similar a esta modalidade.

Um curso a distância deve possuir, além da tecnologia de informação e comunicação, um acompanhamento constante de tutores presenciais e a distância, professores, e demais agentes do curso, como, por exemplo, seus gestores. Deve-se ver o processo de educação a distância de forma sistêmica, onde todas as partes estão integradas.

Nesse sentido, quanto à visão sistêmica na educação a distância, Moore e Kearsley (2007) enfatizam sua importância para o conhecimento sobre essa modalidade de educação.

Doravante, é essencial que as instituições que promovem cursos à distância disponham de órgãos específicos para acompanhamento, atendimento e apoio aos alunos, proporcionando-lhes a aquisição de hábitos e técnicas de estudo, interação com tutores e com outros alunos, afim de, motivá-los a permanecerem no processo de ensino-aprendizagem (Moraes, 2004).

Porém, ao se analisar este sistema de forma mais ampla, outros elementos apresentam-se como essenciais ao processo de acompanhamento ao estudante, como os professores e os gestores. Segundo Reis (1996) os gestores do processo são as pessoas que gerenciam o todo, analisam, supervisionam, controlam e avaliam. O gestor dos processos de $\mathrm{EaD}$ é responsável pela a administração do sistema desenvolvido para dar suporte a todo o trabalho.

Ao relacionarmos a descrição de Reis (1996) sobre os gestores do processo com a tutoria do curso estudado, apresenta-se o papel do Supervisor de Tutoria. Este é responsável pelo gerenciamento, supervisão, avaliação e controle de todo processo dentro do âmbito da tutoria. 


\section{SUPERVISOR DE TUTORIA}

Sob a ótica da Ciência da Administração o Supervisor de Tutoria pode ser classificado como uma função de nível tático (gerencial), onde estaria entre o nível estratégico (coordenação e colegiado do curso) e o nível operacional (tutores presenciais e tutores à distância). $\mathrm{O}$ gerente nas organizações desenvolve uma série de atividades, principalmente as funções clássicas elencadas por Fayol: planejamento, organização, comando, coordenação e controle (Fayol, 1970).

Nesta pesquisa, o Supervisor de Tutoria situa-se na própria instituição de ensino ofertante do curso, sendo responsável pela orientação, acompanhamento e avaliação dos tutores à distância e presencial, bem como do funcionamento do curso. Ressalta-se que o Supervisor de Tutoria executa atividade de cunho administrativo, e não pedagógico. Esta é de responsabilidade do tutor a distância (localizado na instituição ofertante) e do docente responsável pela disciplina ofertada. Dentre as atividades desempenhadas, pelo supervisor de tutoria, apontam-se algumas como primordiais, são elas: contato com os pólos de ensino, criação de relatórios, planejamento do calendário acadêmico, controle de desempenho dos estudantes e tutores, comunicação entre os agentes, coordenação do processo de tutoria e, auxílio no planejamento e desenvolvimento das aulas.

\subsection{Contato com os Pólos}

Uma das características desta modalidade é a distância, não somente espaço entre o docente e o discente, mas também a expansão da estrutura da instituição - neste caso têm-se os pólos de ensino como uma extensão da estrutura matriz da instituição universitária.

A maior parte do contato com os pólos segue um caráter informativo. Visa, primordialmente, a comunicação do cronograma das atividades e o agendamento das mesmas junto aos coordenadores de pólo. As atividades comunicadas são: provas, videoconferências e seminários temáticos, além de trocas de informações de cunho geral entre o Supervisor de Tutoria, Coordenadores de Pólo e Tutores Presenciais.

Tais contatos são importantes para o crescimento do curso e do atendimento ao aluno, pois, nesta modalidade de ensino nem sempre o aluno consegue ter um suporte administrativo eficaz, uma vez que, está distante da instituição ofertante. Devido a frequente utilização de meios digitais na comunição, é necessário apresentar muita clareza e precisão no passar da informação, pois se sabe que a comunicação pode ser um dos grandes problemas da organização.

No curso analisado, a falta comunição entre os agentes é um fator que contribui para o aparecimento de problemas e/ou de falta de informação quanto a determinadas atividades. É verificado que algumas informações de procedimentos encaminhados pela instituição ou informações sobre os alunos oriundos dos pólos de ensino, nem sempre chegam a tempo hábil para a tomada de providencias exigida no caso. Todavia, a conscientização dos envolvidos em relação à importância e urgência do encaminhamento de determinadas informação e ações é sempre ressaltada pelos Coordenadores e Supervisores.

\subsection{Relatórios}

Todos pertencentes a esta instituição devem elaborar relatórios de acordo com suas atividades e funções. A criação dos relatórios, no caso do Supervisor de Tutoria, é decorrente da solicitação da Coordenação de Curso, Departamento de EaD, MEC e 
outras instancias. Tais relatórios geralmente são solicitados para verificar aspectos relacionados ao curso, tais como: situação do aluno (regular, evadido, desistente); taxa de evasão; desempenho e avaliação do curso sobre a ótica de observação dos estudantes; avaliação dos tutores; desempenho do aluno na disciplina $\mathrm{X}$ e no semestre; entre outros aspectos.

O curso ainda não tem um sistema gerencial que ordene as informações (desempenho e situação dos alunos, avaliações, entre outros) que facilite a elaboração destes relatórios. Muitas vezes a busca pelos dados é demorada, porque existe a solicitação das informações em outros setores da instituição. Assim, ressalta-se a importância de um sistema gerencial que mescle os dados (referentes ao curso e discentes) de setores que detém estas informações.

\subsection{Planejamento do calendário acadêmico}

Os pólos de ensino são estruturas externas da instituição de ensino, todavia, no caso da maioria dos cursos a distância o pólo apresenta diversos cursos e instituições. Neste caso, primeiramente é discutido em entre os coordenadores de curso e coordenadores de pólo a "reserva" de dias de semana para cada curso de cada instituição.

A partir dessa divisão de datas, o planejamento do calendário é feito de acordo com a disponibilidade dos pólos. Para a confecção do calendário, principalmente para a aplicação de provas e videoconferências, é necessário discutir com os Coordenadores Pólos para chegar ao um consenso quanto à programação. Pois, em cada região existe uma cultura e costumes a qual muitas vezes a matriz precisa se adaptar - por exemplo, feriados locais e estaduais.

A elaboração deve vir com antecedência, de modo a prevenir alguma não conformidade, como por exemplo, a indisponibilidade de um professor em participar de uma videoconferência. $\mathrm{O}$ calendário leva em conta também a carga horária da disciplina em vigor, se a disciplina apresentar carga horária elevada, o calendário deve ser ampliado para que aconteça um maior número de atividades no pólo.

O mapeamento deste processo pode ser observado na Figura 1, a seguir.

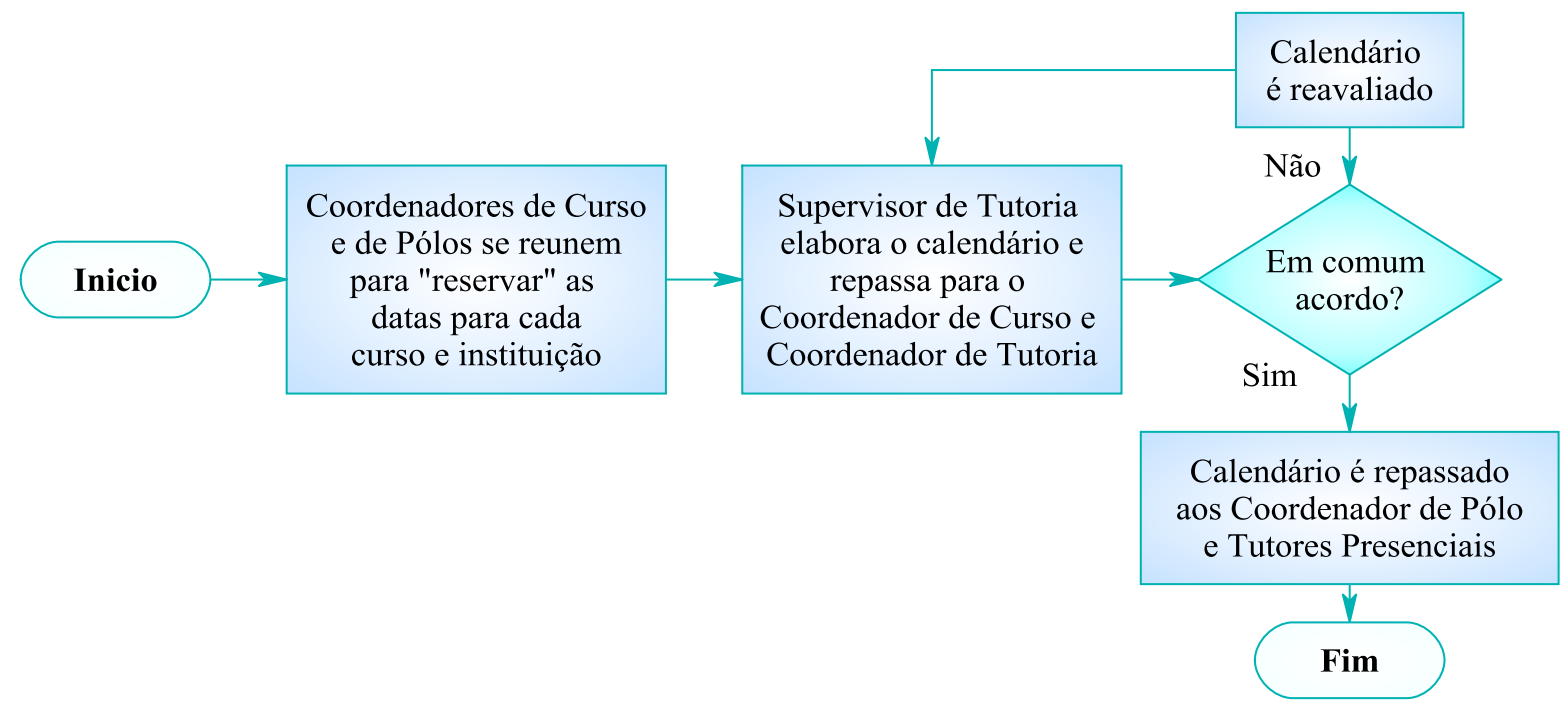

Figura 1: Fluxograma de planejamento do calendário acadêmico Fonte: adaptado de Nunes (2007) 
Neste caso, o planejamento do calendário acadêmico na primeira parte da figura está relacionado à "reserva" de datas para o curso. Posteriormente ele se remete ao planejamento do semestre letivo, estipulando o inicio/término do semestre e das disciplinas. Em seguida é feito o calendário das disciplinas, em consonância com a disponibilidade do docente e com calendário do curso.

O papel do docente na disciplina tem dois momentos, um anterior a oferta e outro durante. No período anterior a oferta o docente elabora o material base para a disciplina (livro-texto) e realiza a gravação de vídeo-aulas que contem o conteúdo da disciplina. Posteriormente, os tutores a distância (os tutores a distância são responsáveis pela orientação do aluno no que tange ao conteúdo, ou seja, aspectos didáticos) leem o livro-texto e assistem as vídeo-aulas, e ficam preparados para a capacitação com o docente. Pós este período, o docente responsável pela disciplina participará de videoconferências e chats com os alunos dos pólos do curso.

A elaboração do calendário acadêmico do curso e da disciplina é um dos problemas vividos pelos Supervisores de Tutoria e Coordenadores. Devido à utilização dos pólos por diversos cursos e instituições há uma saturação do espaço físico do local que muitas vezes não suporta a utilização simultânea de cursos, inviabilizando a execução de atividades em determinada data. Outro ponto crucial para o fechamento do calendário é a disponibilidade do docente. No curso analisado ocorreram diversos problemas em relação à data da oferta da disciplina com a disponibilidade do professor, que nem sempre estão flexíveis quanto às datas das suas atividades presenciais no curso. Bem como, ressalta-se que determinados docentes não estão cientes das características que esta modalidade apresenta e levam a disciplina como um curso qualquer sem comprometimento com o curso, sem rigor no conteúdo e nas avaliações.

\subsection{Controle do desempenho dos estudantes e tutores a distância}

O objetivo das organizações, segundo o principio da administração científica presente até os dias atuais, é o aumento do desempenho. Esta atividade se remete a manter e desenvolver um desempenho mínimo das atividades executadas pelos tutores, além de identificar possíveis quedas de desempenho dos alunos. O controle, como uma função administrativa, procura garantir a qualidade das atividades exercidas pelos tutores; e a melhora/desenvolvimento do aluno e a motivação do mesmo - tendo como pressuposto que nesta modalidade é função também da instituição (coordenadores, supervisores e tutores) incentivar e motivar o aluno.

O controle é realizado por meio do: (a) controle dos estudantes: ambiente virtual (notas das atividades e provas, frequência de acesso), informações pertinentes fornecidas pelos coordenadores de pólos, tutores presenciais e a distância, tais como: assiduidade quanto à entrega de exercícios e presença em dias de prova, participação em videoconferência e chat, dentre outros; (b) controle dos tutores: questionários respondidos pelos estudantes e por uma avaliação informal dos tutores supervisores. A partir das informações coletadas são elaborados relatórios para informar aos coordenadores e demais autoridades o desempenho dos estudantes e tutores.

O processo de acompanhamento e controle do desempenho dos alunos poderá ser visualizado na Figura 2 a seguir. 


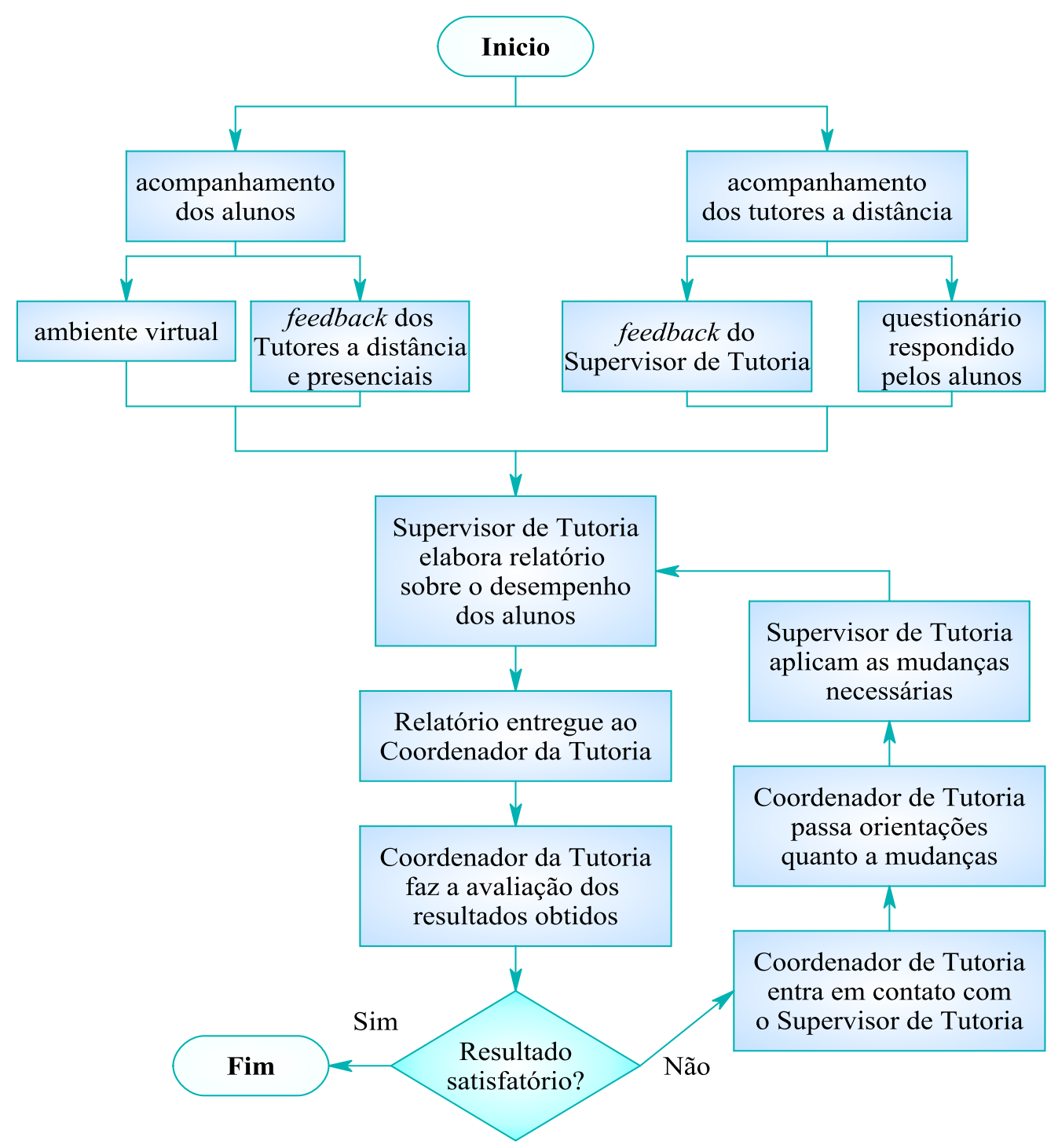

Figura 2: Fluxograma de acompanhamento e avaliação dos alunos e tutores a distância Fonte: adaptado de Nunes (2007)

A figura acima expõe apenas o processo de acompanhamento e avaliação dos alunos e tutores a distância. Já o acompanhamento do Tutor Presencial (executam atividades administrativas, auxiliando o aluno em procedimentos do curso, no ambiente virtual de ensino-aprendizagem, na aplicação de provas, auxilio nas videoconferências, e demais), além do feedback do Supervisor de Tutoria e do questionário respondido pelos alunos, existe o feedback do Coordenador de Pólo e também o Tutor a Distância que estão em contato constante com o aluno. Em relação aos tutores a distância é fundamental um controle mais rigoroso, pois estes são responsáveis pelo acompanhamento acadêmico do aluno, reforçando o conteúdo e respondendo a dúvidas sobre a disciplina, ou seja, são quem os alunos recorrem constantemente.

Falta a aplicação de um método de avaliação mais rigoroso, como um instrumento de avaliação de desempenho que mensure os pontos que necessitam ser trabalhados. Quando mencionado "falta a aplicação" afirma-se que já existe um instrumento elaborado, todavia ainda não se chegou a um consenso da coordenação na aplicação. 


\subsection{Comunicação entre os agentes}

Como já mencionado, a comunicação é de grande importância. E em um curso a distância, ela é fundamental. A comunicação da Supervisão para os agentes envolvidos se desenvolve de várias formas: pessoalmente, por telefone, e-mail e ambiente virtual. As informações repassadas geralmente apresentam um caráter informativo, que visa comunicação de alguma atividade.

Os agentes nos quais o Supervisor de Tutoria mantém contato e as principais informações passadas são: (a) Professores: ajuste de calendário, criação do plano de ensino e atividades, gravação das vídeo-aulas, dentre outros (e-mail e telefone); (b) Tutores a distância e presencial: informações quanto a atividades, calendário e outras (pessoalmente, ambiente virtual, e-mail); (c) Alunos: informações gerais (predominantemente pelo ambiente); (d) Coordenação de Curso: comunicação das atividades desenvolvidas, repasse de relatórios, demonstração dos resultados, entre outros (pessoalmente); (e) Coordenação de pólo: comunicação referente a datas de provas e envio das mesmas, questionamentos em relação aos tutores presenciais e alunos, dentre outras (telefone e e-mail).

Por fim, O processo de comunicação segue-se por uma cadeira hierárquica, onde as principais decisões são tomadas pelo colegiado do curso. Deste modo, as informações ou questões são passadas pelo Coordenador do Curso e em seguida, se cabível, são repassadas para os Supervisores. Na sessão 4.1 já foi mencionado algumas críticas sobre a comunicação, assim esta informação não é repetida nesta sessão.

\subsection{Coordenação do processo de tutoria}

Toda organização necessita de planejamento, organização, controle, comando e coordenação $\left(\mathrm{POC}_{3}\right)$. As funções administrativas de Fayol estão presentes no dia a dia de nossas vidas tanto no lado pessoal quanto profissional. Ao remetermos este pensamento para a organização - a tutoria - pode-se identificar diversas atividades presente neste setor, tanto pedagógicas quanto administrativas.

Tal atividade visa a manter o ambiente em ordem, trata-se de estabelecer "um lugar para cada coisa e cada coisa em seu lugar" ou "um lugar para cada pessoa e cada pessoa em seu lugar". A coordenação é uma atividade que exige conhecimento da própria cultura e regras da organização, além da própria equipe com quem trabalha.

A coordenação do processo de tutoria por si só, pode ser considerada como a atividade macro que abrange todas as outras atividades aqui listadas. Os autores citaram esta atividade para enfatizar a importância do Supervisor na coordenação dos processos realizados na tutoria analisada.

\subsection{Auxilio no planejamento e desenvolvimento das aulas}

O planejamento e desenvolvimento são organizados pelo Coordenador da Tutoria junto com o professor da disciplina, que entram em comum acordo na metodologia que será aplicada. Esta atividade consiste em criar método ou atividades que garantam uma maior participação dos alunos, assim como uma maior frequência. Partindo do pressuposto que determinados métodos didáticos em ressonância com outros fatores podem acarretar em desmotivação e desistência do aluno do curso.

Deste modo, a constante busca e desenvolvimento de novas técnicas e métodos podem garantir uma maior "atratividade" por parte do aluno nas atividades, disciplinas e no curso. O fluxograma representado na Figura 3, a seguir, apresente este processo. 


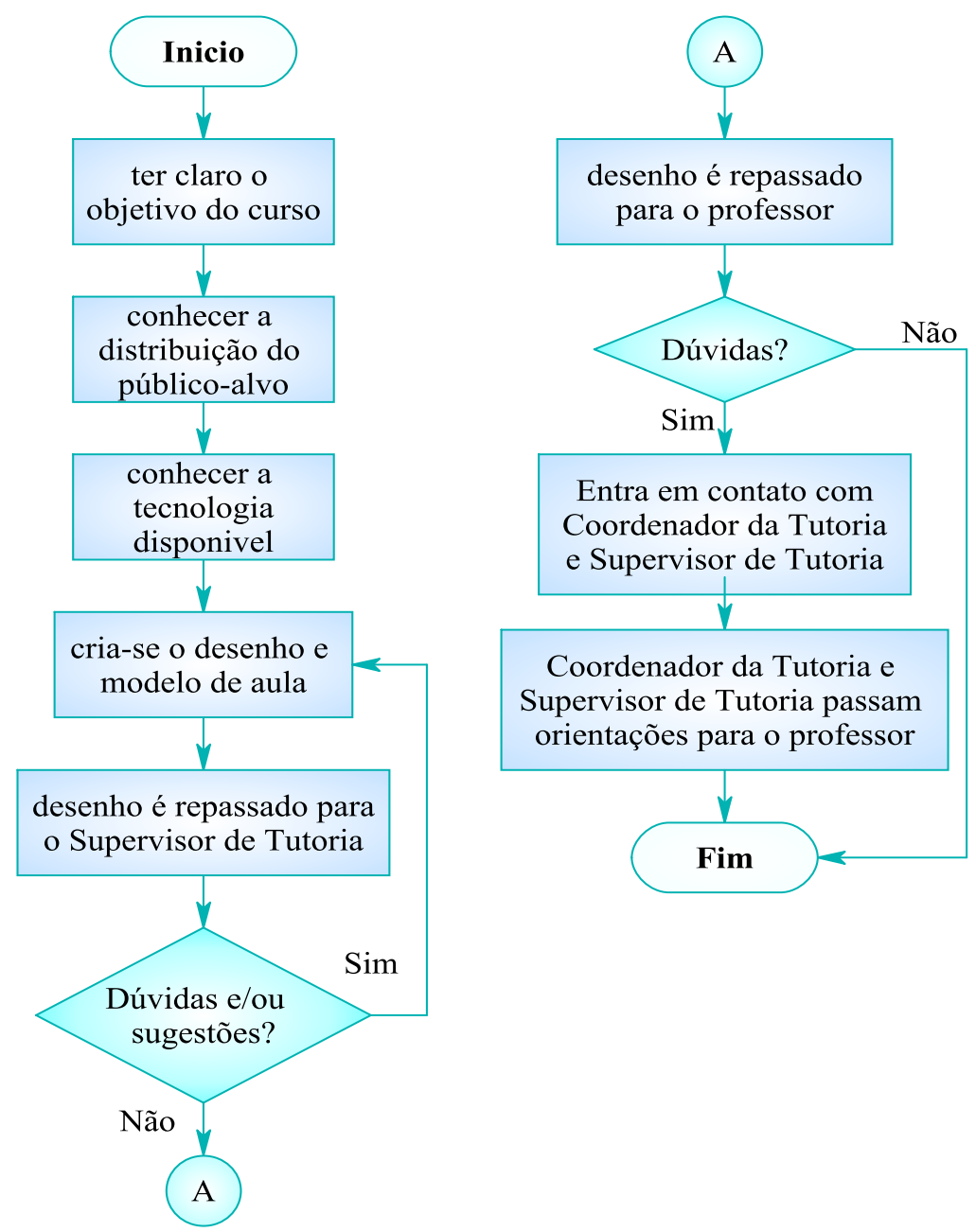

Figura 3: Fluxograma de determinação do desenho das aulas Fonte: Nunes (2007)

O Supervisor de Tutoria entra nesse processo para auxiliar, fornecendo ideias para o desenho das aulas, tanto da metodologia aplicada quanto das atividades. Assim auxiliam no desenvolvimento das aulas, ajudando na criação das vídeo-aulas, na formulação dos exercícios e provas, e na maneira de como o professor deve conduzir as videoconferências. Os Supervisores coletam informações pertinentes dos estudantes e dos próprios tutores para ajudar neste processo.

O curso apresenta uma ferramenta didática que chamamos de vídeo-aulas, ela consiste na gravação (pelo próprio docente) do conteúdo que será ministrado durante a disciplina. Estas aulas gravadas sofreram diversas modificações durante o curso, como posicionamento de câmeras, a exposição de textos de rodapés enquanto é passado o conteúdo e outros. Todas estas para garantir uma maior qualidade e para prender a atenção do aluno no conteúdo. Novas tecnologias estão sempre sendo geradas, cabe à instituição e aos responsáveis buscar estas e adaptá-las a sua necessidade.

\section{CONSIDERAÇÕES FINAIS}

A gestão de um curso a distância não é tarefa fácil, para que esta modalidade tenha uma qualidade faz-se necessário apresentar uma organização eficiente, bem como uma equipe multidisciplinar com profissionais qualificados para atuar. 
Os papeis na $\mathrm{EaD}$ são extensos e cada vez mais crescentes. Contudo, ao verificar a tutoria de um curso identifica-se o Coordenador de Tutoria e os Tutores (presenciais e a distância). No curso analisado, constatou-se o Supervisor de Tutoria como uma função gerencial de significativa importância para o funcionamento do curso, exercendo atividades com: contato com os pólos de ensino, elaboração relatórios, planejamento do calendário acadêmico, controle de desempenho dos estudantes e tutores a distância, comunicação entre os agentes e, auxílio no planejamento e desenvolvimento das aulas. De modo geral, o Supervisor de Tutoria apresenta um papel de ligação e repasse de informações entre a Coordenação do Curso e demais níveis.

Além disso, esta função é exercida normalmente por ex-tutores, que tenham experiência em $\mathrm{EaD}$ e tenham características específicas, como liderança, responsabilidade, comprometimento, pró-atividade, entre outros. Este supervisor tem uma maior autonomia que o tutor, e reporta suas ações ao coordenador, o qual exerce uma atividade mais gerencial/estratégica. Portanto melhora a comunicação e agiliza o processo.

É importante enfatizar que este papel assim como os demais precisa estar em constante comunicação e sintonizados para atender às necessidades gerais do curso. Pois, em sinergia é que esta equipe conseguirá efetivar um curso com qualidade.

Se o gestor estratégico do curso de EaD souber valorizar o supervisor, estará melhorando a qualidade das relações entre os tutores e alunos e consequentemente a qualidade do curso, que é o que se quer atingir.

\section{REFERÊNCIAS}

ARETIO, Lorenzo García. La educación a distancia: de la teoria a la práctica. Barcelona: Ariel. 2002.

FAYOL, Henri. Administração industrial e geral. 8. ed. São Paulo: Atlas, 1970.

GIL, Antônio Carlos. Métodos e técnicas de pesquisa social. 5. ed. São Paulo: Atlas, 2007.

MOORE, Michael; KEARSLEY, Greg. Educação a distância: uma visão integrada. São Paulo: Thomson, 2007.

MORAES, Marialice de. Universidade Federal de Santa Catarina. Programa de PósGraduação em Engenharia de Produção. A monitoria como serviço de apoio ao aluno na educação a distância. Florianópolis, 2004. 229f. Tese (Doutorado) - Universidade Federal de Santa Catarina, Centro Tecnológico. Programa de Pós-Graduação em Engenharia de Produção.

MORAES, Marialice et al.. Guia Geral do Curso Gestão e Docência em EaD: Programa Aberta-Sul. Florianópolis: UFSC/UFSM, 2007.

NUNES, Thiago Soares. Padronização de Processos: um estudo de caso no curso de Graduação em Administração à Distância. 2007. 125f. Trabalho de Conclusão de Estágio (Graduação em Administração). Curso de Administração, Universidade Federal de Santa Catarina, Florianópolis, 2007.

REIS, Ana Maria Viegas. Ensino a Distância: megatendência atual: abolindo preconceitos. São Paulo: Imobiliária. 1996.

RUMBLE, Greville. A gestão dos sistemas de ensino a distância. Brasília: Universidade de Brasília: Unesco, 2003.

SIMONSON, Michael. Teoría, investigación y educación a distancia. In: BARBERÀ, Elena. Educación abierta y a distancia. Barcelona: UOC, 2006.

UNESCO. Aprendizagem aberta e a distância: perspectivas e considerações políticas educacionais. Florianópolis: Imprensa Universitária, UFSC, 1997. 